framum

Sociológico

\section{Forum Sociológico}

Série II

$19 \mid 2009$

As Forças Armadas numa sociedade em mudança

\title{
A profissionalização das Forças Armadas: um olhar sobre o seu pilar de sustentação - os militares do regime de voluntariado e de contrato
}

António Ideias Cardoso, Isabel Madeira, Francisco Sousa Marques, Cristina Poças Vilhena, Luís Vicente Baptista, José Manuel Resende, Paulo Antunes Ferreira e Patrícia Pereira

\section{(2) OpenEdition \\ Journals}

Edição electrónica

URL: https://journals.openedition.org/sociologico/338

DOI: $10.4000 /$ sociologico.338

ISSN: 2182-7427

Editora

CICS.NOVA - Centro Interdisciplinar de Ciências Sociais da Universidade Nova de Lisboa

Edição impressa

Data de publição: 1 junho 2009

Paginação: $37-48$

ISSN: 0872-8380

Refêrencia eletrónica

António Ideias Cardoso, Isabel Madeira, Francisco Sousa Marques, Cristina Poças Vilhena, Luís Vicente Baptista, José Manuel Resende, Paulo Antunes Ferreira e Patrícia Pereira, «A profissionalização das Forças Armadas: um olhar sobre o seu pilar de sustentação - os militares do regime de voluntariado e de contrato», Forum Sociológico [Online], 19 | 2009, posto online no dia 20 julho 2012, consultado o 30 março 2022. URL: http://journals.openedition.org/sociologico/338 ; DOI: https://doi.org/10.4000/sociologico.338

Este documento foi criado de forma automática no dia 30 março 2022.

(c) CICS.NOVA 


\section{A profissionalização das Forças Armadas: um olhar sobre o seu pilar de sustentação - os militares do regime de voluntariado e de contrato}

António Ideias Cardoso, Isabel Madeira, Francisco Sousa Marques, Cristina Poças Vilhena, Luís Vicente Baptista, José Manuel Resende, Paulo Antunes Ferreira e Patrícia Pereira

\section{Introdução}

1 Portugal incorporou a mudança de paradigma organizacional rumo à profissionalização do serviço militar, tendo, em pouco mais de 10 anos, alterado profundamente a composição do seu efectivo militar. Assim, em 1993, o nosso país tinha quase 78 mil militares. Doze anos depois, já após o fim da conscrição e com a total implementação da profissionalização, o número de efectivos passou para cerca de 37 mil profissionais. 
Gráfico 1: Evolução do efectivo militar das Forças Armadas

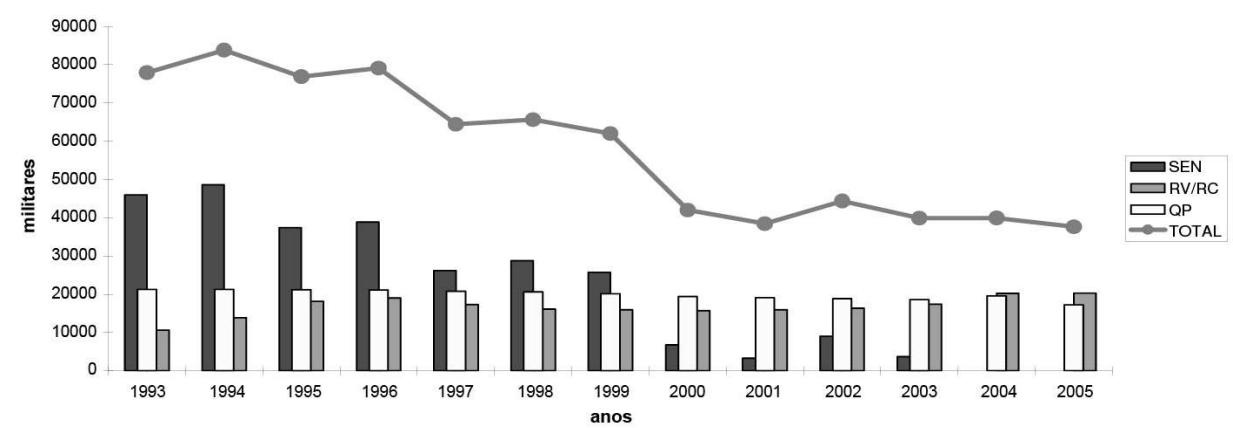

FONTE: Anuários Estatísticos do Ministério da Defesa Nacional de 1993 a 2005

2 Independentemente da interpretação qualitativa que se possa realizar desta profunda mudança, pode afirmar-se que a implementação da profissionalização está a consolidarse.

Devido a esta especificidade, o modelo de profissionalização exige às Forças Armadas uma contínua capacidade para cativar os efectivos necessários à prossecução das suas actividades, numa perspectiva quantitativa e qualitativa. Para que as Forças Armadas não venham a enfrentar situações de falta de efectivos, a profissionalização deve ser vista como uma missão permanente, trabalhada de forma sequencial, sustentada e integrada. Por outro lado, para que os indivíduos que deixam as Forças Armadas no final do seu contrato não se vejam confrontados com um mercado de trabalho para o qual não adquiriram, devido à sua inserção na instituição militar, as competências e as qualificações necessárias, a formação adequada destes indivíduos deve ser também uma prioridade das Forças Armadas. O número e complexidade destas novas variáveis levaram à necessidade de uma gestão de recursos humanos mais complexa e necessariamente mais conhecedora da realidade, não permitindo lugar para o ensaio de soluções ad hoc sustentadas em contextos passados. Foi neste contexto que surgiu o estudo que suporta este artigo, o qual teve por objectivos não apenas a caracterização sociográfica destes militares, mas também a apreensão das suas lógicas de acção, a caracterização e interpretação dos processos de estruturação de trajectórias profissionais e o conhecimento dos mecanismos de tomada de decisão.

\section{Características do universo de estudo}

4 O universo sobre o qual incidiu este trabalho constitui-se nos militares do Regime de Voluntariado e de Contrato (RV/RC) dos três ramos das Forças Armadas Portuguesas (Marinha, Exército e Força Aérea), abrangendo, em termos globais, 20521 militares, embora, em termos proporcionais, os ramos apresentem dimensões bastante diferentes entre si. O Exército é o ramo que apresenta o maior volume de população neste Regime, 14456 militares, pertencendo à Força Aérea 3342 e à Marinha 2723 militares. Para o estudo deste universo foi construída uma amostra estratificada e proporcional (dentro de cada ramo), desenhada para garantir uma análise representativa de cada um dos ramos $^{1}$. 
Tabela 1: Total de efectivos em RV/RC por ramo

\begin{tabular}{|l|l|l|l|l|l|l|}
\hline \multicolumn{4}{|l|}{ Ramo } & \multicolumn{4}{l|}{ MARINHA } & \multicolumn{2}{l|}{ EXÉRCITO } & \multicolumn{2}{l|}{ FORÇA AÉREA } \\
\hline Categoria & Efectivos $^{2}$ & Amostra & Efectivos $^{2}$ & Amostra & Efectivos & Amostra \\
\hline Oficiais & 254 & & 596 & & 533 & \\
\hline Sargentos & 26 & & 1290 & & 10 & \\
\hline Praças & 2443 & & 12570 & & 2799 & \\
\hline Total & $\mathbf{2 7 2 3}$ & $\mathbf{9 4 0}$ & $\mathbf{1 4} 456$ & $\mathbf{1 2 4 0}$ & $\mathbf{3 3 4 2}$ & $\mathbf{9 0 0}$ \\
\hline
\end{tabular}

\section{Dados sócio-demográficos}

5 Relativamente à distribuição da variável sexo em cada um dos ramos, o Gráfico 2 permite identificar aspectos de alguma relevância. Em primeiro lugar, constata-se que os três ramos das Forças Armadas apresentam uma composição marcadamente masculina, uma vez que a percentagem mais baixa de militares do sexo masculino é de $71,4 \%$, registada na Força Aérea. Em segundo lugar, apesar deste predomínio de um dos sexos, verifica-se uma diferença assinalável entre os ramos em matéria de peso proporcional de homens e mulheres, sendo a Força Aérea o ramo que apresenta a maior percentagem de mulheres $(28,6 \%)$ e a Marinha o que apresenta a menor (14\%). 0 Exército ocupa nesta matéria uma posição intermédia, embora mais próxima da apresentada pela Marinha.

Gráfico 2: Distribuição da variável sexo dos militares RC por ramo, em \%

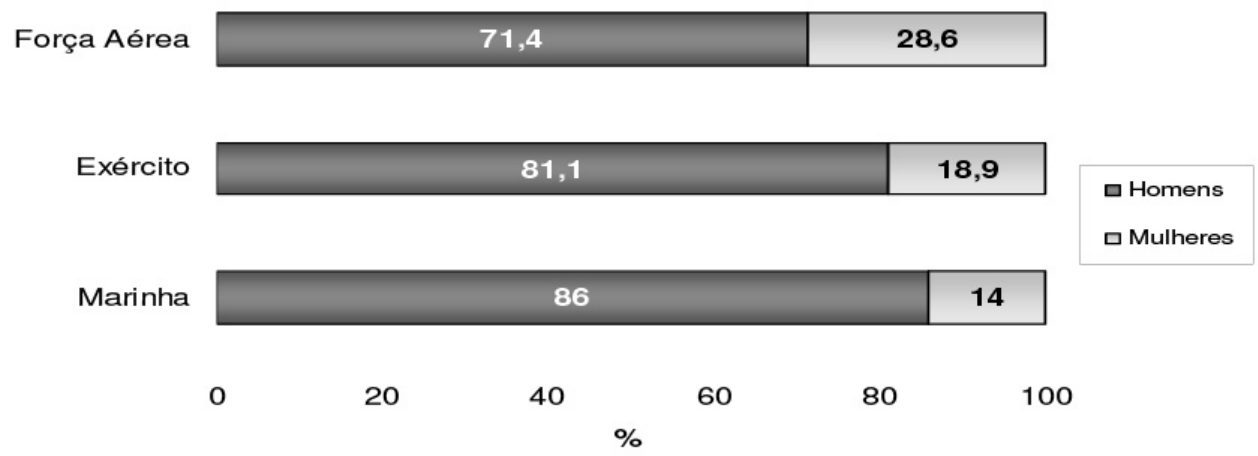

6 No que concerne à idade dos militares no momento da inquirição, a Tabela 2 mostra uma ligeira diferença entre a população que compõe cada um dos ramos, da qual transparece que os militares da Força Aérea apresentam uma média de idade superior à dos restantes: 24,08 anos, contra 23,12 dos militares do Exército e 22,02 dos militares da Marinha. 
Tabela 2 : Média de idades dos militares RC por ramo (em anos) ${ }^{3}$

\begin{tabular}{|l|l|l|}
\hline & \multicolumn{2}{|l|}{ Média de Idades (em anos) } \\
\hline Ramo & Idade actual & Idade de ingresso \\
\hline Marinha & 22,02 & 19,98 \\
\hline Exército & 23,12 & 20,06 \\
\hline Força Aérea & 24,08 & 20,23 \\
\hline
\end{tabular}

7 O último aspecto de natureza sócio-demográfica considerado em matéria de caracterização da população em estudo é o nível de escolaridade actual dos militares de cada um dos ramos. A este propósito, os dados disponíveis expressos na Tabela 3 revelam a existência de um perfil de escolarização bastante diferenciado entre os ramos.

8 Em primeiro lugar, verifica-se que Marinha e Força Aérea apresentam o 12. ano como nível de escolaridade predominante, embora com uma expressão diferenciada favorável para este último ramo, respectivamente $40,7 \%$ e $50 \%$. O Exército, relativamente a este nível de escolaridade, apresenta uma percentagem bastante inferior não ultrapassando os $28 \%$. Aliás, este ramo apresenta como nível de escolaridade predominante o 9.ำ ano, com 35,5\% aos quais correspondem 23,6\% na Marinha e apenas 10,2\% na Força Aérea.

9 Os extremos da variável "Nível de Escolaridade" também distinguem os ramos. No extremo inferior, referente a quem apresenta menos que o 9.. de escolaridade, a percentagem registada pelo Exército é de 10,6\%, contra 2,2\% na Marinha e sem ocorrências na Força Aérea. Já em relação a quem tem um nível de Licenciatura ou superior, a situação inverte-se, sendo a Força Aérea o ramo que apresenta o valor mais elevado: $11,6 \%$, contra 6,5\% da Marinha e 3,5\% no Exército.

Tabela 3 : Nível de escolaridade actual dos militares em cada um dos ramos

\begin{tabular}{|c|c|c|c|c|}
\hline & \multicolumn{3}{|c|}{ Ramo a que pertence } & \multirow[b]{2}{*}{ Total } \\
\hline & Marinha & Exército & Força Aérea & \\
\hline Menos que o $9 .{ }^{\circ}$ ano & $\begin{array}{r}21 \\
2,2 \% \\
\end{array}$ & $\begin{array}{r}131 \\
10,6 \%\end{array}$ & $\begin{array}{r}0 \\
, 0 \% \\
\end{array}$ & $\begin{array}{r}152 \\
\mathbf{4 , 9 \%} \\
\end{array}$ \\
\hline $9 .{ }^{\circ}$ ano & $\begin{array}{r}221 \\
23,6 \%\end{array}$ & $\begin{array}{r}438 \\
35,5 \%\end{array}$ & $\begin{array}{r}92 \\
10,2 \%\end{array}$ & $\begin{array}{r}751 \\
\mathbf{2 4 , 5 \%}\end{array}$ \\
\hline $10 .^{\circ}$ ano & $\begin{array}{r}103 \\
\mathbf{1 1}, \mathbf{0} \% \\
\end{array}$ & $\begin{array}{r}123 \\
\mathbf{1 0 , 0 \%} \\
\end{array}$ & $\begin{array}{r}49 \\
5,5 \% \\
\end{array}$ & $\begin{array}{r}275 \\
9,0 \% \\
\end{array}$ \\
\hline 11.0 ano & $\begin{array}{r}150 \\
16,0 \% \\
\end{array}$ & $\begin{array}{r}159 \\
12,9 \% \\
\end{array}$ & $\begin{array}{r}204 \\
22,7 \% \\
\end{array}$ & $\begin{array}{r}513 \\
16,7 \% \\
\end{array}$ \\
\hline $12 .^{\circ}$ ano & $\begin{array}{r}382 \\
40,7 \% \\
\end{array}$ & $\begin{array}{r}341 \\
27,6 \%\end{array}$ & $\begin{array}{r}449 \\
\mathbf{5 0 , 0} \% \\
\end{array}$ & $\begin{array}{r}1172 \\
\mathbf{3 8 , 2 \%} \\
\end{array}$ \\
\hline Licenciatura ou superior & $\begin{array}{r}61 \\
6,5 \%\end{array}$ & $\begin{array}{r}43 \\
\mathbf{3}, \mathbf{5} \% \\
\end{array}$ & $\begin{array}{r}104 \\
11,6 \%\end{array}$ & $\begin{array}{r}208 \\
\mathbf{6 , 8 \%}\end{array}$ \\
\hline Total & $\begin{array}{r}938 \\
100,0 \%\end{array}$ & $\begin{array}{r}1235 \\
100,0 \%\end{array}$ & $\begin{array}{r}898 \\
100,0 \%\end{array}$ & $\begin{array}{r}3071 \\
100,0 \%\end{array}$ \\
\hline
\end{tabular}




\section{Caracterização do percurso desenvolvido antes do ingresso nas Forças Armadas}

10 Com o intuito de melhor interpretar as características dos percursos dos indivíduos que integram o Regime de Voluntariado e de Contrato no seio de cada um dos ramos das Forças Armadas, bem como as motivações e justificações que estão na origem de determinados comportamentos, importa considerar os elementos mais expressivos do percurso escolar e profissional que antecedeu o seu ingresso nas Forças Armadas. Conhecer o trajecto que os trouxe até às Forças Armadas poderá ser um importante elemento de enquadramento e compreensão das trajectórias que nelas desenvolvem.

11 Neste sentido, tomámos como ponto de partida de análise a situação profissional anterior ao ingresso nas Forças Armadas. Os resultados obtidos apontam para uma relativa diferença entre os militares que ingressaram em cada um dos ramos das Forças Armadas. Os que ingressaram na Marinha e na Força Aérea encontravam-se maioritariamente na situação de "Estudante", 47\% e 48,6\% respectivamente, ao passo que no Exército essa percentagem se situa nos $36,6 \%$. Confirmando a tendência identificada, o Exército destaca-se como o ramo com maior percentagem de militares que estavam já inseridos no mercado de trabalho antes do ingresso nas Forças Armadas $(36,8 \%)$.

Tabela 4: Situação profissional antes do ingresso por ramo

\begin{tabular}{|c|r|r|r|r|}
\cline { 2 - 4 } \multicolumn{1}{c|}{} & \multicolumn{3}{c|}{ Ramo a que pertence } & \multicolumn{1}{c|}{} \\
\cline { 2 - 4 } \multicolumn{1}{c|}{} & Marinha & Exército & Força Aérea & \multicolumn{1}{c|}{ Total } \\
\hline Estudante & 436 & 452 & 436 & 1324 \\
\hline Trabalhador-estudante & $\mathbf{4 7 , 0 \%}$ & $\mathbf{3 6 , 6 \%}$ & $\mathbf{4 8 , 6 \%}$ & $\mathbf{4 3 , 2 \%}$ \\
& 161 & 176 & 180 & 517 \\
\hline Desempregado & $17,3 \%$ & $14,2 \%$ & $20,0 \%$ & $16,9 \%$ \\
\hline A trabalhar & 46 & 90 & 44 & 180 \\
& $5,0 \%$ & $7,3 \%$ & $4,9 \%$ & $5,9 \%$ \\
\hline Total & 285 & 518 & 238 & 1041 \\
\hline & $\mathbf{3 0 , 7 \%}$ & $\mathbf{4 1 , 9 \%}$ & $\mathbf{2 6 , 5 \%}$ & $\mathbf{3 4 , 0 \%}$ \\
\hline & $100,0 \%$ & $100,0 \%$ & $100,0 \%$ & $100,0 \%$ \\
\hline
\end{tabular}

12 A percentagem de população, em cada ramo, oriunda de uma situação em que o exercício de uma actividade profissional era conciliado com a prossecução de estudos ganha relevância por ser a terceira categoria mais expressiva em todos eles, mas igualmente por ser menos expressiva no Exército comparativamente aos restantes ramos, confirmando, uma vez mais, que a população que integra as fileiras do Exército, por via do Regime de Voluntariado e de Contrato, é a que mostra uma maior taxa de inserção no mercado de trabalho anterior ao ingresso. Por fim, há a registar que, de facto, não é a situação de desemprego que determina o ingresso de forma directa, dado que nenhum dos ramos apresenta uma percentagem muito significativa de militares desempregados antes do ingresso nas Forças Armadas.

Sintetizando as características dos percursos escolares e profissionais que antecederam o ingresso nas Forças Armadas, pode dizer-se que os militares que foram incorporados no Exército se distinguem por apresentarem menores níveis de escolaridade e uma maior ligação ao mercado de trabalho, ao passo que os militares da Força Aérea se 
constituem como os mais escolarizados e de menor experiência profissional. A Marinha ocupa uma posição intermédia nesta matéria, embora tenha a maior percentagem de militares que frequentaram formação profissional.

\section{Os processos de escolha no âmbito do percurso desenvolvido nas Forças Armadas}

O percurso profissional desenvolvido pelos militares é caracterizado por um conjunto de escolhas sucessivas, desde a escolha em ingressar nas Forças Armadas à escolha do ramo em que esse ingresso é efectuado e mesmo às actividades que se pretende desenvolver. $\mathrm{O}$ objectivo deste ponto passa por analisar e compreender esses processos, procurando apreender os factores em que assentam, como variam e como se integram nas trajectórias profissionais dos indivíduos. A pertinência desta análise reside no facto de estas escolhas representarem opções vinculativas em termos de trajectórias profissionais.

\section{Motivos de ingresso no RV/RC}

Um dos momentos mais marcantes no percurso profissional de um militar é aquele em que é efectivamente tomada a decisão de ingressar nas Forças Armadas. Como tal, parece oportuno iniciar a análise pelos motivos apresentados pelos militares para justificar essa sua opção. Pretende-se verificar até que ponto se trata de uma decisão assente na avaliação comparada de diversas oportunidades profissionais e se inscreve numa trajectória profissional com contornos delineados.

Os dados disponíveis permitem conhecer o perfil de motivos apontados para o ingresso em cada um dos ramos. Através deles, é possível verificar que a atracção pelas actividades e missões das Forças Armadas e a participação na defesa e representação do país são os motivos de ingresso mais transversais aos três ramos e, ao mesmo tempo, os mais significativos para cada um.

Em termos das especificidades de cada um dos ramos verifica-se que, para quem ingressa na Força Aérea ou na Marinha, obter segurança profissional é um motivo de elevada relevância, o que, em virtude de se estar perante uma proposta de emprego com uma duração máxima definida à partida (sensivelmente 6 anos), aponta para a precariedade e insegurança profissional com que estes jovens militares representam o mercado de emprego. Para os militares destes dois ramos, assume ainda alguma relevância a justificação de ingresso que se baseia na pretensão de ter uma profissão remunerada. Trata-se de uma outra forma de perspectivar o ingresso, igualmente assente numa componente utilitária. No caso ainda do ingresso na Marinha, é também de destacar a importância atribuída a aspectos relacionados com as representações sobre o ramo, nomeadamente as características da vida militar que lhe são inerentes e o facto de proporcionar conhecer novos lugares. São dois motivos justificativos que distinguem os militares deste ramo face aos restantes.

Tabela 5: Motivos justificativos do ingresso em RV/RC em cada um dos ramos

(valor médio) ${ }^{5}$ 


\begin{tabular}{|l|l|l|l|}
\hline ITEM & Marinha & Exército & $\begin{array}{l}\text { Força } \\
\text { Aérea }\end{array}$ \\
\hline Atracção pelas actividades e missões das Forças Armadas & $\mathbf{5 , 5 0}$ & $\mathbf{5 , 4 3}$ & $\mathbf{5 , 2 3}$ \\
\hline Obter segurança profissional & $\mathbf{5 , 3 7}$ & 4,74 & $\mathbf{5 , 4 4}$ \\
\hline Atracção pelas características da vida militar & $\mathbf{5 , 1 5}$ & 4,75 & 4,99 \\
\hline Servir o país/Participar na defesa e representação do país & 5,43 & 5,22 & $\mathbf{5 , 1 6}$ \\
\hline Não ter emprego & 2,56 & 2,49 & 2,69 \\
\hline Não conseguir arranjar outro emprego & 2,14 & 2,09 & 2,19 \\
\hline Para sair de casa ou da região & 1,89 & 1,86 & 1,90 \\
\hline Por tradição ou influência familiar & 2,48 & 2,42 & 2,25 \\
\hline Por ter amigos nas Forças Armadas & 2,71 & 2,69 & 2,32 \\
\hline Para beneficiar dos incentivos à prestação de serviço em & 4,11 & 3,96 & 4,19 \\
\hline RV/RC & 4,57 & $\mathbf{4 , 0 2}$ & $\mathbf{4 , 7 0}$ \\
\hline Para ter uma profissão remunerada & $\mathbf{5 , 2 4}$ & 3,77 & 4,03 \\
\hline Pelo prestígio social dos militares & 4,46 & 4,14 \\
\hline Para conhecer novos lugares & & & \\
\hline
\end{tabular}

Tabela 6: Agregação dos motivos de ingresso em factores (por semelhança estatística) ${ }^{6}$

\begin{tabular}{|l|l|l|l|l|}
\hline \multicolumn{4}{|l|}{ Factores } \\
\hline & $\mathbf{1}$ & $\mathbf{2}$ & $\mathbf{2}$ & \multicolumn{2}{l}{$\mathbf{4}$} \\
\hline Atracção pelas actividades e missões das Forças Armadas &, $\mathbf{8 2 9}$ &, 062 &,- 060 &, 053 \\
\hline Obter alguma segurança profissional &, 312 &, $\mathbf{6 6 0}$ &, 093 &,- 095 \\
\hline Atracção pelos valores característicos da vida militar &, $\mathbf{8 2 2}$ &, 198 &,- 034 &, 059 \\
\hline Servir Portugal/participar na defesa e representação do país &, $\mathbf{8 3 7}$ &, 135 &,- 060 &, 095 \\
\hline Não ter emprego/estar sem fazer nada &,- 067 &, 180 &, $\mathbf{8 4 9}$ &,- 020 \\
\hline Não conseguir arranjar outro tipo de emprego &,- 092 &, 138 &, $\mathbf{8 6 2}$ &, 032 \\
\hline Sair de casa e da área de residência &, 078 &, 014 &, $\mathbf{6 4 3}$ &, 356 \\
\hline Tradição ou influência familiar &, 122 &, 059 &, 094 &, $\mathbf{7 9 6}$ \\
\hline
\end{tabular}




\begin{tabular}{|l|c|c|c|c|}
\hline Ter amigos nas Forças Armadas &, 072 &, 194 &, 089 & $\mathbf{8 0 5}$ \\
\hline Beneficiar dos incentivos à prestação de serviço militar &, 043 &, 758 &, 026 &, 243 \\
\hline Obter uma profissão remunerada &, 033 &, $\mathbf{8 3 3}$ &, 220 &, 049 \\
\hline Prestígio social dos militares &, 383 &, $\mathbf{6 2 8}$ &, 087 &, 261 \\
\hline Possibilidade de conhecer novos lugares &, $\mathbf{4 3 6}$ &, 362 &, 116 &, 285 \\
\hline
\end{tabular}

Os militares que ingressaram no Exército apresentam a particularidade de atribuir uma importância significativa a um número mais reduzido de motivos justificativos. Os motivos mais referidos pelos militares deste ramo são os que foram anteriormente apontados como transversais aos três ramos e assentam sobretudo em imagens e representações do ramo, ficando sub-representados os motivos ligados a ganhos ou possíveis benefícios profissionais inerentes ao ingresso nas Forças Armadas.

19 Para analisar de forma mais aprofundada este conjunto de motivos de ingresso e identificar os elementos que os poderão fazer variar, procedeu-se à realização de uma Análise Factorial, de forma a constituir grupos de factores estatisticamente semelhantes, reduzindo assim a complexidade dos dados. Dos resultados da aplicação deste procedimento emerge a agregação dos vários motivos de ingresso considerados em quatro factores, que apresentam a configuração apresentada na Tabela 6.

Tendo em consideração a configuração dos factores, o primeiro foi designado como atracção pelas características da vida e profissão militar; o segundo por benefícios profissionais e sociais inerentes ao desempenho da actividade militar; o terceiro como influência da rede social e o quarto como ausência de outras perspectivas de natureza profissional. Em termos de capacidade explicativa, no seu conjunto, estes quatro factores explicam $65,7 \%$ da variância total dos motivos de ingresso, o que é muito significativo. Destes quatro factores, os mais relevantes são o primeiro, que denominamos por atracção pelas características da vida e profissão militar, com 30,4\%, e o segundo, entendido como benefícios profissionais e sociais inerentes ao desempenho da actividade militar, com $17,3 \%$, o que em conjunto perfaz $47,7 \%$. O terceiro e o quarto factores, ou seja, a influência da rede social e a ausência de outras perspectivas profissionais, apesar de estatisticamente significativos, em conjunto, explicam apenas $18 \%$ da variância total. Estes dados vêm solidificar o que a análise de médias de cada um dos motivos tinha já permitido antever.

21 Posteriormente, para cada um destes factores foram procurados elementos de influência ou variação teoricamente pertinentes face aos objectivos do estudo e às características da população observada, tais como o ramo das Forças Armadas a que os militares pertencem e, no interior de cada ramo, o sexo e escolaridade dos militares.

Relativamente à variação das várias dimensões justificativas do ingresso pelo ramo, a análise dos dados apresentados nos Gráficos 3 e 4 confirma o que já tinha sido revelado pelas análises anteriormente efectuadas. Os motivos associados às características da vida militar, apesar de serem transversais aos três ramos e de se apresentarem como os mais expressivos em cada um deles, têm um peso ligeiramente superior no caso da Marinha, sendo esta diferença estatisticamente significativa. Por outro lado, o ingresso justificado com base em benefícios sociais e profissionais inerentes ao desempenho da 
actividade militar é menos expressivo no Exército, comparativamente à Marinha e à Força Aérea, assumindo a diferença registada o estatuto de estatisticamente significativa.

Gráfico 3: Ingresso pela atracção das características da vida e profissão militar

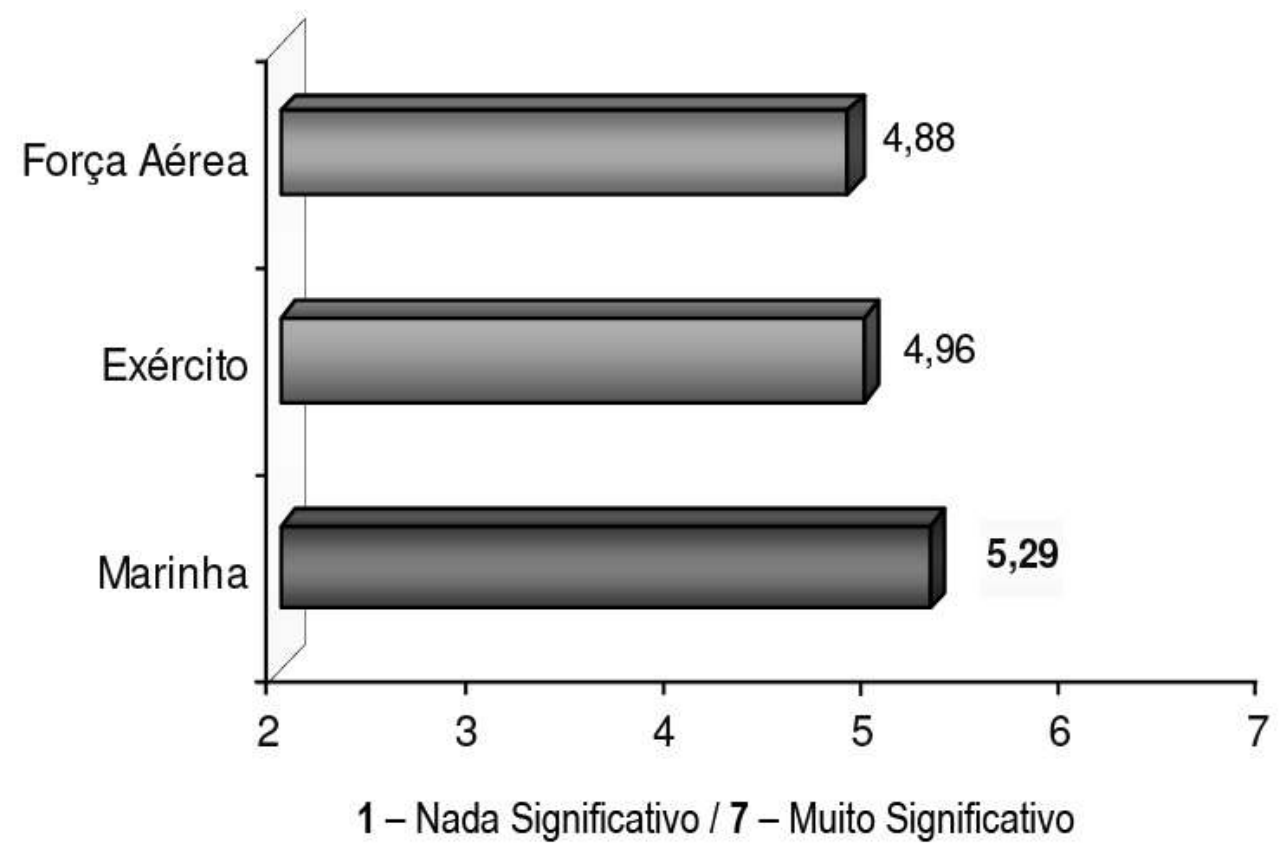

$F=26.006 \quad p=0.000$

GRÁfico 4: Ingresso por benefícios profissionais e sociais

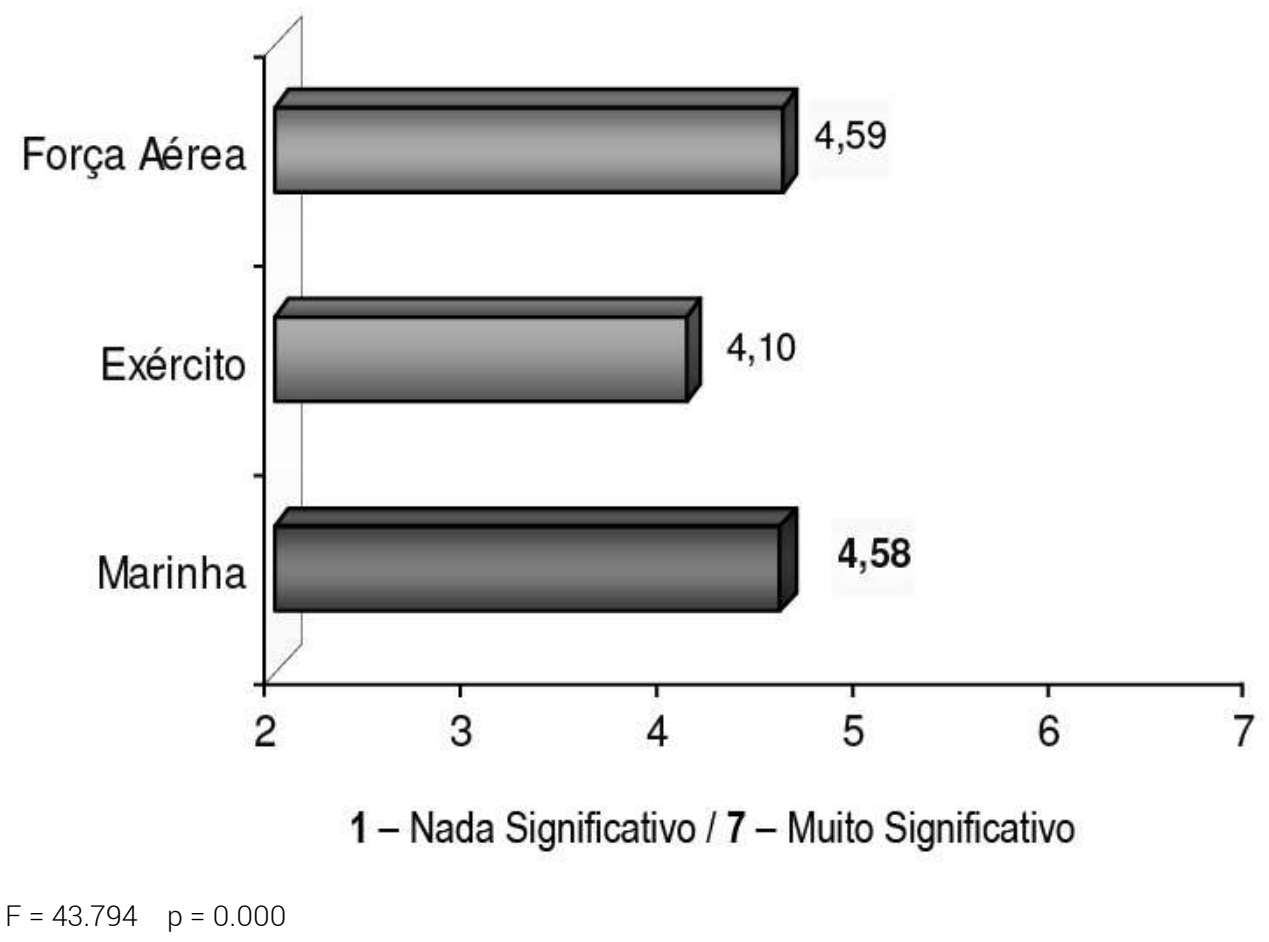


No que concerne à influência da rede social dos militares como justificação para o ingresso, bem como à justificação desse ingresso por falta de outras perspectivas profissionais, os valores registados por estes dois factores não são expressivos em nenhum dos ramos, dado que ou são negativos $(<2,5)$ ou se encontram no limiar da positividade $(>2,5)$. Relativamente à variação dos vários factores de ingresso em cada um dos ramos das Forças Armadas em função do sexo dos militares, as análises efectuadas não revelaram a existência de diferenças significativas. No que concerne à influência da escolaridade dos militares de cada um dos ramos na justificação do ingresso, as análises efectuadas permitiram extrair algumas tendências de variação relevantes. Em cada um dos ramos notou-se que os militares mais escolarizados (licenciatura ou superior) têm menos tendência a dar como justificação para o ingresso a atracção pelas características da vida e profissão militar. Importa ainda referir que em nenhum dos ramos se verificaram diferenças de relevo em função do nível de escolaridade relativamente à justificação através dos benefícios sociais e profissionais, o que lhes confere um carácter mais transversal.

\section{Razões apontadas para a escolha do ramo}

Se a compreensão dos factores que estão na base da decisão de ingressar nas Forças Armadas, como se viu no ponto anterior, fornece indicadores importantes para definir os contornos que poderá assumir a trajectória profissional desenvolvida pelos militares, a análise dos factores em que assenta a escolha do ramo confere-lhes um importante grau de objectividade e de materialização.

27 No que concerne a resultados, importa desde já afirmar que, ao contrário da análise da justificação do ingresso nas Forças Armadas, onde foi possível encontrar um conjunto de elementos justificativos transversais aos três ramos, a justificação de escolha do ramo apresenta uma maior diferenciação.

A Tabela 7 mostra que a opção pelo ingresso na Marinha é justificada pelo facto de proporcionar conhecer novos lugares $(42,6 \%)$, mas também pela formação que proporciona $(35,3 \%)$ e pelas missões que desenvolve no país (30,7\%).

Tabela 7: Razões justificativas para a escolha do ramo

\begin{tabular}{|l|l|l|l|}
\hline \multicolumn{3}{|l|}{$(\%)^{7}$} \\
\hline ITEM & Marinha & Exército & Força Aérea \\
\hline Por ser o mais adequado às qualificações que possuía & 13 & 16,5 & $\mathbf{2 4 , 7}$ \\
\hline Pela formação profissional que proporciona & $\mathbf{3 5 , 3}$ & $\mathbf{1 1}$ & $\mathbf{5 2 , 7}$ \\
\hline Pelos equipamentos que o caracterizam & 6,2 & 6 & 17,4 \\
\hline Pelas missões de paz em que participa & 24,5 & $\mathbf{4 6 , 4}$ & 9,3 \\
\hline Por proporcionar conhecer novos lugares & $\mathbf{4 2 , 6}$ & 15,1 & 9,4 \\
\hline
\end{tabular}




\begin{tabular}{|l|l|l|l|}
\hline Pelas missões que desenvolve no país & $\mathbf{3 0 , 7}$ & $\mathbf{2 7 , 6}$ & 22,1 \\
\hline Por ter unidades perto da zona de residência & 12,2 & $\mathbf{2 4 , 9}$ & 9,3 \\
\hline Por não ter vagas noutro & 3 & 8,2 & 2,2 \\
\hline Pela influência de familiares ou amigos & $\mathbf{2 6 , 3}$ & 19,9 & $\mathbf{2 9 , 4}$ \\
\hline Por ter amigos nesse ramo & 11,5 & 11,6 & 10,4 \\
\hline Pelo prestígio do ramo & $\mathbf{2 6 , 7}$ & $\mathbf{9}$ & $\mathbf{3 7 , 7}$ \\
\hline Pelo rigor e disciplina & $\mathbf{1 8 , 2}$ & $\mathbf{1 8 , 8}$ & 10,4 \\
\hline Número de inquiridos por ramo (N) & 939 & 1242 & 900 \\
\hline
\end{tabular}

Para o ingresso no Exército as principais razões apontadas são as missões de apoio à paz em que participa $(46,4 \%)$, seguidas das missões que desenvolve no país $(27,6 \%)$, bem como o facto de este ramo ter Unidades/Estabelecimentos e Órgãos por todo o país e, consequentemente, mais próximas das regiões de proveniência dos indivíduos (24,9\%). As três principais justificações apresentadas pelos militares do Exército distanciam claramente este ramo dos restantes.

Relativamente ao ingresso na Força Aérea, verifica-se que, essencialmente, é justificado pela formação profissional que proporciona $(52,7 \%)$, um aspecto que distingue claramente este ramo dos demais, sobretudo do Exército. O prestígio social do ramo também apresenta um valor significativo $(37,7 \%)$ e distintivo face aos restantes ramos. É de realçar ainda o facto de $24,7 \%$ dos jovens que ingressam neste ramo apontarem como elemento justificativo a sua maior adequação às qualificações que detinham, o que aponta para uma ideia de continuidade de um percurso escolar e profissional que parece estar menos presente nos restantes ramos.

31 Um outro aspecto que importa destacar prende-se com o papel desempenhado pela influência de familiares ou amigos na escolha do ramo, não só por ser bem mais expressiva na justificação da decisão de ingressar no RV/RC, mas também porque traduz uma expressividade diferente consoante o ramo, sendo mais vincada na Força Aérea $(29,4 \%)$ e na Marinha (26,3\%) do que no Exército (19,9\%).

Feita a análise geral relativa aos motivos mais importantes em que assenta a escolha do ramo, interessa agora aprofundá-la, através de técnicas estatísticas adequadas, analisando o que distingue os três ramos, bem como os aspectos que podem fazer variar esses mesmos motivos. Neste sentido, foi efectuada uma análise de correspondências múltiplas entre todas as razões de escolha do ramo consideradas (o próprio ramo, o sexo e a escolaridade dos militares), com o intuito de identificar quais os perfis de razões e características que mais distinguem cada um dos ramos.

Os resultados obtidos, expressos no Gráfico 8, permitem efectuar um conjunto de reflexões não só sobre o posicionamento diferenciado de cada um dos ramos nos planos do Gráfico, mas também sobre as razões de ingresso e os níveis de escolaridade que lhes estão mais associados. 

diferentes do Gráfico e que lhes estão associados um conjunto de razões de carácter distintivo, dado que nenhum deles está próximo da zona neutra (o ponto zero). No que concerne aos aspectos específicos, constata-se que, associado ao ingresso na Marinha, surge um perfil de razões que se pode considerar misto, dado que engloba elementos ligados à formação que o ramo ministra e às saídas profissionais que proporciona. Verifica-se também uma aproximação às características da vida militar, através das missões desenvolvidas pelo ramo no país ou devido ao facto de proporcionar o conhecimento de novos lugares. Em termos escolares, verifica-se que este ramo não é escolhido por ser o mais adequado às qualificações dos militares, mas também que não se caracteriza por ser o preferido dos menos escolarizados. Não sendo tão escolarizados como os da Força Aérea, os militares da Marinha demonstram ter ambições escolares e formativas, o que se verifica pela proximidade do elemento "não adequação do ramo às qualificações pessoais". Os dados mostram ainda não existir, nos militares deste ramo, conformismo em relação às suas qualificações, mas sim sinais evidentes de estratégias de incremento. Este é, aliás, um dos pontos que justifica o facto de militares da Marinha e do Exército se situarem em quadrantes que, tecnicamente, se designam por opostos.

Especificando a situação dos militares do Exército, pode constatar-se que este ramo se situa no quadrante positivo da dimensão referente às características da vida militar e se distingue dos restantes por ser o que mais atrai os indivíduos menos escolarizados, os que querem participar em missões de paz e os que assentam a sua escolha na atracção pelos valores do rigor e da disciplina, ou no facto de ser o ramo que tem Unidades/ Estabelecimentos e Órgãos mais próximos da zona de residência de origem.

e-se que a sua localização no Gráfico, para além de oposta à Marinha, apresenta a particularidade de ser tecnicamente simétrica à Força Aérea, por partilhar com este ramo uma posição positiva na dimensão respeitante à adequação face às qualificações pessoais. No entanto, dada a configuração, trata-se de uma adequação que se dá com níveis baixos de qualificação, ou seja, são menos escolarizados, mas estão relativamente conformados com esse facto, escolhendo o Exército por ser o ramo que, em termos de representação, melhor se adequa à sua situação.

Aprofundando a análise relativamente à escolha da Força Aérea, verifica-se que esta assume como factores distintivos a sua adequação às qualificações dos militares, bem como uma maior associação aos níveis mais elevados de escolaridade, nomeadamente Licenciatura e 12. ano. Trata-se assim de um ramo que é escolhido porque se ajusta às qualificações de partida, sendo estas de nível elevado, o que parece predizer uma estratégia de rentabilização do percurso escolar desenvolvido por estes militares.

Importa ainda referir que, relativamente a diferenças entre os universos feminino e masculino, se denota que o primeiro está mais próximo de um perfil de escolhas associado à Força Aérea, isto é, que assenta na rentabilização das qualificações de partida, ao passo que o segundo, não apresentando um perfil de escolhas tão claro, assume uma postura mais positiva face às especificidades da vida militar, sem que sejam associáveis de forma nítida ao perfil de qualquer ramo. 


\section{Como os militares RV/RC projectam o seu futuro profissional}

Neste ponto de desenvolvimento do trabalho, parece oportuno tentar apreender como a população em estudo conjuga motivos de ingresso, factores de escolha e percurso desenvolvido para delinear o seu futuro profissional, procurando perceber o papel dos ramos nessa projecção e traçar as configurações gerais que as trajectórias profissionais podem assumir em função do ramo a que os militares pertencem.

Tratando-se de projecções para o futuro, construídas com base em experiências vividas, permitirão, também, analisar a coerência de sentido que se estabelece entre escolhas, percurso desenvolvido e perspectivas. Este processo de inserção das escolhas numa trajectória traduz o que Giddens denomina de colonização do futuro ou arrastamento do tempo futuro para o tempo presente, o que se constitui, aliás, como um traço da época actual marcada por uma cultura de projecto (Giddens, 1994). O projecto pode ser conceptualizado como a representação de objectivos ou desejos futuros que, partindo de experiências passadas, organiza e confere sentido às acções presentes e quotidianas. $\mathrm{Na}$ sua elaboração, encontra-se uma dinâmica que resulta do cruzamento das dimensões individual e social. Os projectos individuais não são puramente internos e subjectivos, são definidos dentro de um contexto social e cultural, emergindo de um quadro de possibilidades. É através dos projectos que as trajectórias se constroem, o que faz destes um objecto de estudo com especial relevo.

Gráfico 8: Razões para escolha do ramo - a definição de perfis

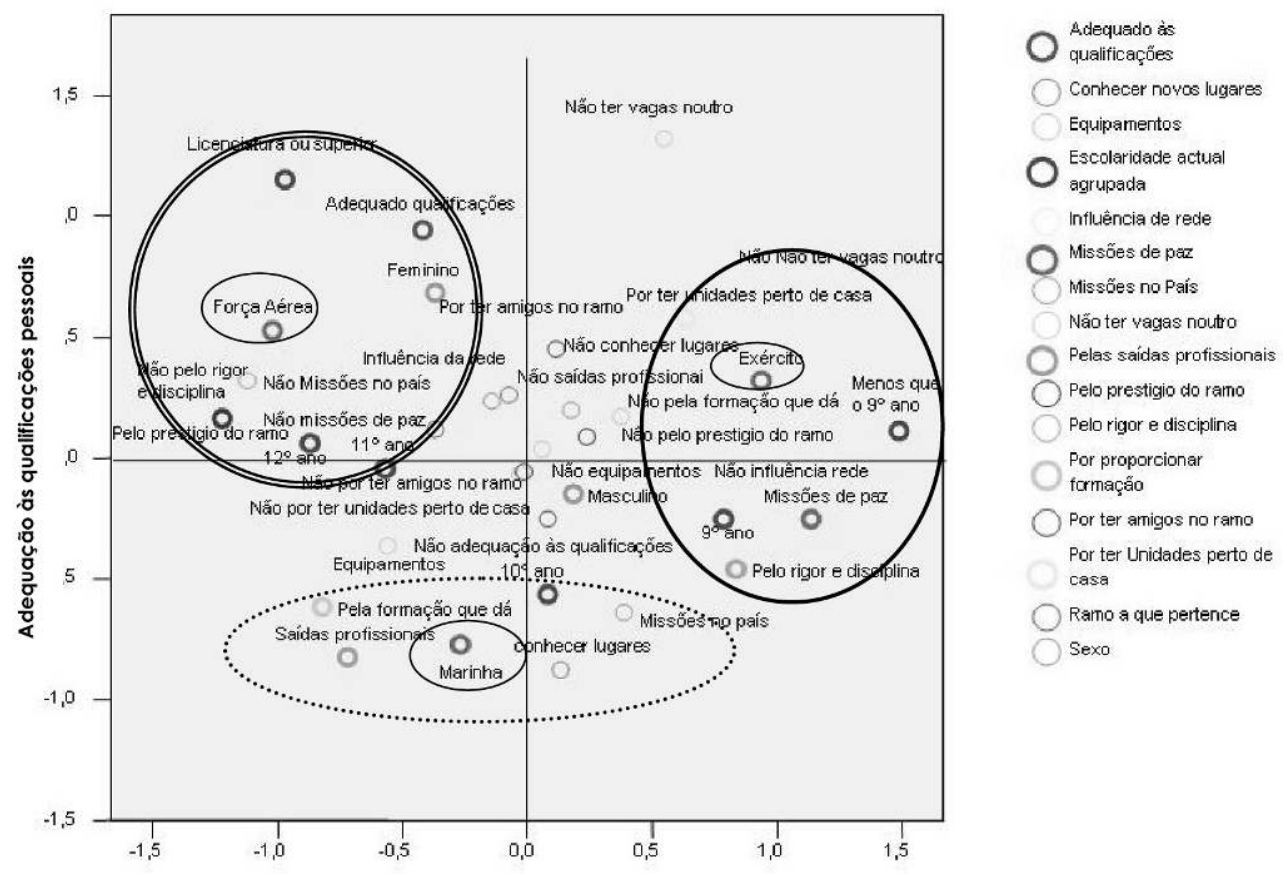

\section{As perspectivas profissionais}

Para operacionalizar esta reflexão, partindo do resultado da análise que os militares fazem entre as suas expectativas futuras e a informação de que dispõem acerca das 
possibilidades efectivas de realização das mesmas, procuramos analisar quais os pilares em que assenta o projecto futuro dos militares, bem como as suas possíveis variações.

Importa salientar que a perspectiva teórica que norteia o processo de análise das trajectórias profissionais que se desenvolvem tendo os ramos das Forças Armadas como elementos intervenientes aponta para a possibilidade de definição de uma tipologia construída a partir da noção de projecto, enquanto acção orientada em conformidade com valores num dado contexto histórico, para dar conta das decisões sucessivas tomadas pelo actor na sua trajectória de inserção nas Forças Armadas (Hubert JeanPierre Thomas apud Prevot-Forni, 2001: 30).

Um primeiro tipo, se assim se pode chamar, tenderá para a instrumentalização, mais ou menos racional, da finalidade da profissão militar. Trata-se de um tipo de trajectória que incide na procura de uma qualificação transferível para o mercado de trabalho civil, que integra a ideia não de pertença total, mas de passagem pelas Forças Armadas, sendo por isso caracterizada por uma menor interiorização dos deveres e valores da instituição militar.

Um segundo tipo de trajectória assentará num investimento importante na continuidade da actividade profissional militar, sendo por isso marcado por uma maior identificação e implicação com a instituição militar. Caracteriza-se também por escolhas de especialidades funcionais com menor capacidade de transferibilidade para o mercado de trabalho civil, o que implica definições de si centradas na identidade militar.

Estudos realizados nas Forças Armadas francesas, tendo por base esta perspectiva teórica, permitiram dar conta de que, de facto, as Forças Armadas são capazes de despertar o interesse de jovens que visam projectos identitários muito diferentes, porque as imagens por elas projectadas oferecem um conjunto diversificado de suportes que parecem ajudar a formular as suas expectativas e a fornecer-lhes marcadores que participam na definição da identidade pretendida (Léger, 2003: 722), verificando-se, contudo, uma certa predominância da tendência instrumental.

Não sendo nossa pretensão testar ou aferir o potencial explicativo das propostas teóricas em que assentou a concepção do processo de investigação, a interpretação dos dados referentes às trajectórias profissionais projectadas e desenvolvidas pelos militares à luz da tipologia referida, pela dimensão de comparabilidade que possibilita, confere-lhes maior relevância.

Assim, em termos de resultados, analisando a Tabela 8 verifica-se que as intenções futuras dos militares em termos profissionais divergem em função do ramo a que pertencem e a grande divergência prende-se com o papel que as Forças Armadas, ou o ramo em particular, desempenham nesse projecto. Neste sentido, verifica-se que a maioria dos militares da Marinha e da Força Aérea, 58,5\% e 57,5\%, respectivamente, têm como objectivo ingressar no quadro permanente das Forças Armadas, desenvolvendo assim um projecto profissional de integração plena na instituição. Em sentido oposto, apenas $15,5 \%$ dos militares do Exército manifestam uma intenção análoga, distribuindo-se as suas principais pretensões pelo ingresso nas Forças de Segurança $(25,3 \%)$, pela criação do próprio emprego (16\%) e pelo ingresso na Função Pública (12,5\%). 
Tabela 8: Bases para o projecto futuro dos militares de cada um dos ramos

\begin{tabular}{|c|c|c|c|c|}
\hline & \multicolumn{3}{|c|}{ Ramo a que pertence } & \multirow[b]{2}{*}{ Total } \\
\hline & Marinha & Exército & Força Aérea & \\
\hline Criar o próprio emprego & $\begin{array}{r}68 \\
7,4 \%\end{array}$ & $\begin{array}{r}191 \\
16,0 \%\end{array}$ & $\begin{array}{r}58 \\
6,6 \%\end{array}$ & $\begin{array}{r}317 \\
10,6 \%\end{array}$ \\
\hline Ingressar na Função Pública & $\begin{array}{r}33 \\
3,6 \%\end{array}$ & 149 & $\begin{array}{r}54 \\
6,1 \%\end{array}$ & $\begin{array}{r}236 \\
7,9 \%\end{array}$ \\
\hline Ingressar nas Forças de Segurança & $\begin{array}{r}113 \\
12,3 \% \\
\end{array}$ & 302 & $\begin{array}{r}62 \\
7,1 \% \\
\end{array}$ & $\begin{array}{r}477 \\
15,9 \%\end{array}$ \\
\hline Ingressar no Quadro Permanente das Forças Armadas & $\begin{array}{r}539 \\
<\mathbf{5 8 , 5 \%} \\
\end{array}$ & 185 & $\begin{array}{r}505 \\
\mathbf{5 7}, \mathbf{5} \% \\
\end{array}$ & \begin{tabular}{r|r|}
1229 \\
$41,0 \%$
\end{tabular} \\
\hline Ingressar numa empresa privada & $\begin{array}{r}24 \\
2,6 \%\end{array}$ & $\begin{array}{r}102 \\
8,5 \%\end{array}$ & $\begin{array}{r}63 \\
7,2 \%\end{array}$ & $\begin{array}{r}189 \\
6,3 \%\end{array}$ \\
\hline Finalizar estudos superiores & $\begin{array}{r}106 \\
11,5 \% \\
\end{array}$ & $\begin{array}{r}129 \\
10,8 \% \\
\end{array}$ & $\begin{array}{r}108 \\
12,3 \% \\
\end{array}$ & $\begin{array}{r}343 \\
11,5 \% \\
\end{array}$ \\
\hline Emigrar para outro país & $\begin{array}{r}23 \\
2,5 \% \\
\end{array}$ & $\begin{array}{r}88 \\
7,4 \%\end{array}$ & $\begin{array}{r}12 \\
1,4 \%\end{array}$ & $\begin{array}{r}123 \\
4,1 \% \\
\end{array}$ \\
\hline $\begin{array}{l}\text { Recorrer ao subsídio de desemprego/não ter } \\
\text { projecto profissional }\end{array}$ & $\begin{array}{r}7 \\
8 \% \\
\end{array}$ & $\begin{array}{r}31 \\
2,6 \% \\
\end{array}$ & $\begin{array}{r}3 \\
, 3 \% \\
\end{array}$ & $\begin{array}{r}41 \\
1,4 \% \\
\end{array}$ \\
\hline Outra & $\begin{array}{r}9 \\
1,0 \% \\
\end{array}$ & $\begin{array}{r}17 \\
1,4 \% \\
\end{array}$ & $\begin{array}{r}14 \\
1,6 \% \\
\end{array}$ & $\begin{array}{r}40 \\
1,3 \%\end{array}$ \\
\hline Total & $\begin{array}{r}922 \\
100,0 \%\end{array}$ & $\begin{array}{r}1194 \\
100,0 \%\end{array}$ & $\begin{array}{r}879 \\
100,0 \%\end{array}$ & $\begin{array}{r}2995 \\
100,0 \%\end{array}$ \\
\hline
\end{tabular}

Para melhor compreender estes resultados importa ter em consideração que as possibilidades efectivas de ingressar nos Quadros Permanentes dos ramos são algo diferentes em cada um deles. Além da possibilidade de ingressar nos Quadros Permanentes através dos concursos para as categorias de oficiais e Sargentos, que têm uma percentagem significativa de vagas cativada para militares do regime de voluntariado e contrato, que se verifica nos três ramos, a Marinha tem ainda um Quadro Permanente para a categoria de Praças. Certamente que os resultados obtidos são condicionados por este tipo de informação, mas não será de desprezar o papel da valorização que os militares de cada um dos ramos fazem do percurso profissional até então desenvolvido.

Para tentar contornar o efeito de variáveis situacionais descritas anteriormente, os militares foram questionados sobre qual seria o seu projecto de futuro, mas num contexto em que cada um dos cenários que lhes era apresentado tinha realização garantida. Os resultados obtidos, que constam da Tabela 9, não são muito diferentes dos anteriormente explanados. Nos casos da Marinha e da Força Aérea, o cenário preferido pela maioria dos militares continua a ser o ingresso nos Quadros Permanentes das Forças Armadas, o que significa que mesmo num plano em que pudessem escolher outras opções o seu futuro continuaria a passar, maioritariamente, pela integração permanente nas Forças Armadas. 
Tabela 9: O futuro dos militares de cada um dos ramos - cenário de preferência

\begin{tabular}{|c|c|c|c|c|}
\hline & \multicolumn{3}{|c|}{ Ramo a que pertence } & \multirow[b]{2}{*}{ Total } \\
\hline & Marinha & Exército & Força Aérea & \\
\hline Criar o próprio emprego & $\begin{array}{r}130 \\
13,9 \% \\
\end{array}$ & $\begin{array}{r}248 \\
20,3 \% \\
\end{array}$ & $\begin{array}{r}135 \\
15,1 \% \\
\end{array}$ & $\begin{array}{r}513 \\
16,8 \%\end{array}$ \\
\hline Ingressar na Função Pública & $\begin{array}{r}47 \\
5,0 \% \\
\end{array}$ & $\begin{array}{r}112 \\
9,2 \% \\
\end{array}$ & $\begin{array}{r}55 \\
6,2 \% \\
\end{array}$ & $\begin{array}{r}214 \\
7,0 \% \\
\end{array}$ \\
\hline Ingressar na GNR & $\begin{array}{r}111 \\
11,9 \% \\
\end{array}$ & $\begin{array}{r}321 \\
26,3 \%\end{array}$ & $\begin{array}{r}68 \\
7,6 \% \\
\end{array}$ & $\begin{array}{r}500 \\
16,4 \% \\
\end{array}$ \\
\hline Ingressar na PSP & $\begin{array}{r}72 \\
7,7 \% \\
\end{array}$ & $\begin{array}{r}98 \\
8,0 \% \\
\end{array}$ & $\begin{array}{r}30 \\
3,4 \% \\
\end{array}$ & $\begin{array}{r}200 \\
6,6 \% \\
\end{array}$ \\
\hline Ingressar no Quadro Permanente das Forças Armadas & $\begin{array}{r}523 \\
56,1 \% \\
\end{array}$ & \begin{tabular}{r|}
329 \\
$27,0 \%$ \\
\end{tabular} & $\begin{array}{r}492 \\
55,0 \% \\
\end{array}$ & $\begin{array}{r}1344 \\
44,1 \% \\
\end{array}$ \\
\hline Ingressar no quadro de uma empresa privada & $\begin{array}{r}50 \\
5,4 \% \\
\end{array}$ & $\begin{array}{r}112 \\
9,2 \% \\
\end{array}$ & $\begin{array}{r}114 \\
\mathbf{1 2 , 8} \% \\
\end{array}$ & $\begin{array}{r}276 \\
9,1 \% \\
\end{array}$ \\
\hline Total & $\begin{array}{r}933 \\
100,0 \% \\
\end{array}$ & $\begin{array}{r}1220 \\
100,0 \% \\
\end{array}$ & $\begin{array}{r}894 \\
100,0 \% \\
\end{array}$ & $\begin{array}{r}3047 \\
100,0 \% \\
\end{array}$ \\
\hline
\end{tabular}

50 Por outro lado, no caso do Exército assiste-se a um acréscimo da percentagem de militares que optariam pela integração no Quadro Permanente, mas está longe de ser o cenário referenciado pela maioria, ficando-se pelos $27 \%$, havendo $26,3 \%$ que optariam pelo ingresso na GNR e 20,3\% que encetariam a criação do próprio emprego. Assim, também aqui se pode dizer que, mesmo que tal fosse garantido, o futuro profissional dos militares do Exército passaria menos pela integração plena no ramo e mais por outro tipo de cenários.

51 Em síntese, pode dizer-se que os projectos de integração plena nas Forças Armadas são diferentes consoante o ramo a que os militares pertencem, sendo na Força Aérea e na Marinha muito mais vincados que no Exército.

Comparando com a tipologia apresentada no início deste ponto, a realidade das Forças Armadas portuguesas apresenta como elemento inovador o facto de os jovens recrutados para especialidades tipicamente militares serem aqueles que surgem mais associados às trajectórias de tipo instrumental. 0 recrutamento para estas especialidades é realizado em ruptura com o mundo civil e incide sobre jovens pouco qualificados, cuja identificação ao papel de soldado corresponde à sua definição de virilidade. Estes jovens encontram no exercício desta profissão uma forma de opor uma alternativa socialmente aceite ao modo de selecção do sistema de ensino com o qual foram até aí confrontados e contra o qual esbarraram.

53 Por outro lado, ao ingresso orientado para uma especialidade técnica com equivalência no mercado de trabalho, fundado numa procura de valorização profissional do percurso e qualificações escolares, surgem mais associadas trajectórias que visam a integração. Assim, estratégias que assentaram o ingresso em escolhas justificadas por uma maior aproximação às características da vida e actividade militar não têm sequência em termos de projecção de futuro, porque acabam por culminar numa saída ou numa passagem para as Forças de Segurança, enquanto estratégias que pareciam assentar numa matriz instrumental das Forças Armadas acabam por visar a integração permanente.

\section{Notas conclusivas}

54 No que respeita às características sócio-demográficas, um aspecto relevante é o nível de escolaridade actual dos militares de cada um dos ramos, tendo ficado demonstrada a existência de um perfil escolar bastante diferenciado entre os ramos. A Marinha e a 
Força Aérea apresentam o 12. ano como nível de escolaridade predominante, 40,7\% e $50 \%$, respectivamente. O Exército apresenta uma percentagem bastante inferior relativamente a este nível de escolaridade, na ordem dos $28 \%$, apresentando como nível de escolaridade predominante o $9 .^{\circ}$ ano, com 35,5\%. Ainda em matéria de qualificações, importa reter o facto de as mulheres, em qualquer dos ramos, apresentarem, em média, níveis de escolaridade superiores aos dos homens.

No domínio das motivações de ingresso nas Forças Armadas e da justificação das escolhas profissionais efectuadas pelos militares, seja em termos de ramo ou de área de actividade, também se tornaram visíveis diferenças muito significativas. O ingresso no Exército assenta essencialmente em elementos associados à atracção pelas características da profissão e da vida militar, tais como a participação em missões de paz, a atracção por valores como o rigor e a disciplina, e pelo facto de existir maior proximidade entre as Unidades/Estabelecimentos e Órgãos militares e a zona de residência. Por outro lado, o ingresso na Marinha e na Força Aérea é fundamentado por critérios relacionados com as qualificações escolares e profissionais, seja por estratégias de valorização nesta matéria, como é o caso da Marinha, seja por uma lógica de adequação das funções às qualificações de partida, como é o caso da Força Aérea. Relativamente à escolha das áreas de actividade, a interpretação segue o mesmo padrão, sendo no entanto de ressalvar a percentagem de militares do Exército que nesta matéria não têm qualquer intervenção, cabendo a decisão ao ramo.

Um outro conjunto de dados analisados e que se reveste de uma importância significativa para a compreensão da relação dos militares com o ramo das Forças Armadas a que pertencem prende-se com a compreensão do papel que este desempenha nas trajectórias profissionais projectadas pelos militares. A este propósito foram detectadas diferenças muito significativas em função do ramo a que os militares pertencem, salientando-se uma maior identificação com projectos futuros que passam pela permanência na instituição militar por parte dos militares que integram a Marinha e a Força Aérea e um forte interesse em ingressar nas Forças de Segurança apresentado pelos do Exército.

Dados recolhidos entre Maio e Junho de 2007.

\section{BIBLIOGRAFIA}

BALTAZAR, M. S. (2005), As Forças Armadas Portuguesas: desafios numa sociedade em mudança, Casal de Cambra, Edições Caleidoscópio.

BENOÎT-GUILBOT, O. e J.-V. Pfirsch (1998), La decision d'engagement volontaire des militaires du rang: L'armée de terre, Paris, Ed. Centre d'études en sciences sociales de la défense.

BERNETE, F. (2003), “Ejército profesional y distanciamento civil de la Defensa”, International de Sociología, 38, Madrid, CSIC.

BOENE, B. (2003), “La professionnalisation des armées”, Revue française de sociologie, 44-4, Paris, Ophrys. 
BOENE, B. e C. Dandecker (2001), Les armées professionnelles et le liens armée-Etat-société, au RoyaumeUni, Paris, Ed. Centre d'études en sciences sociales de la défense.

CARREIRAS, H. (2004), "Diversidade social nas Forças Armadas”, Revista Nação e Defesa, 107, Lisboa, Instituto da Defesa Nacional.

DUBAR, C. (2006), A Crise das Identidades, Porto, Edições Afrontamento.

GIDDENS, A. (1994), As consequências da modernidade, Oeiras, Celta Editora.

GRESLE, F. (2003), “La société militaire aujourd'hui”, Revue française de sociologie, 44-4, Paris, Ophrys.

LABATUT, B. e J. Martinez Paricio (2003), La professionnalisation des armées en Espagne: consequences des mutations du système d'hommes sur la politique militaire et sur les relations civilo-militaires, Paris, Ed. Centre d'études en sciences sociales de la défense.

LÉGER, J.-F. (2003), “Les Jeunes engagés”, Revue française de sociologie, 44-4, Paris, Ophrys.

NÚÑEZ, N. (2000), El Soldado profesional en España, Madrid, Tese de Doutoramento, policopiado, Madrid, Universidad Complutense (F.C.P.S).

PFIRSCH, J.-V. (Coord.), G. Bozec e J. Naudet (2003), Cinq ans après, que sont devenues les engagés volontaires de l'armée de terre? Étude de cohorte, Paris, Ed. Centre d'études en sciences sociales de la défense.

PREVOT-FORNI, E. (2001), L'identité militaire à l'épreuve des operations extérieures à finalité pacificatrice: l'exemple d'un régiment d'infanterie, Paris, Ed. Centre d'études en sciences sociales de la défense.

\section{NOTAS}

1. Para cada uma das amostras o nível de confiança foi de $97 \%$ e o limite máximo do erro amostral foi de $3 \%$.

2. Dados dos ramos a 31 de Março de 2007.

3. Quantitativos de referência (N): Marinha - 940; Exército - 1240; Força Aérea - 900.

4. Calculada subtraindo o n.o de anos de serviço à idade actual.

5. Escala: 1 - Nada Importante; 7 - Muito Importante.

6. Os valores do quadro representam a correlação parcial de cada motivo com cada um dos factores extraídos. Os motivos agregam-se ao factor com o qual têm a correlação mais elevada (mais próxima do valor 1). Para a rotação dos dados foi usado o método "varimax".

7. Cada item totaliza $100 \%$ por si só em cada um dos ramos.

\section{RESUMOS}

A realidade internacional em que as estruturas de defesa das nações ocidentais tradicionalmente operavam sofreu uma mudança paradoxal com o fim da Guerra Fria. Instalou-se uma nova realidade geoestratégica pautada pela incerteza e pelo carácter multipolar e global dos conflitos, 
que as confrontou com a incapacidade de resposta dos seus tradicionais exércitos de massas, cuja vocação se baseava essencialmente na defesa territorial e que eram alimentados, essencialmente, através de mecanismos de conscrição. Um sistema de forças de dimensão mais reduzida, tecnologicamente mais desenvolvido e adaptável, quer na sua integração em forças multinacionais, quer na sua capacidade de tradução e adaptação aos contextos em que é chamado a intervir, implica necessariamente umas Forças Armadas compostas de efectivos altamente preparados e totalmente profissionais na sua acção.

o que se apresenta neste artigo é uma reflexão sobre a forma como este processo de profissionalização tem sido vivido e desenvolvido pelas Forças Armadas Portuguesas, dando especial ênfase aos seus verdadeiros protagonistas: os militares. Quem são, porque ingressam, e quais as suas expectativas são as perguntas a que tentamos dar uma hipótese de resposta.

After the end of the Cold War the international reality in which the structures of defence of Western nations have traditionally operated in suffered a paradoxical change. Inserted in a new geo-strategic reality ruled by uncertainty and multiple and global conflicts, the military organizations confronted themselves with the inability of their traditional mass armies - whose task was based primarily on territorial defence and were fed primarily through mechanisms of conscription, to respond to this new adversities and conflicts. A smaller, more technologically and developed system of forces, both in terms of their integration in the multinational forces and in its ability to translate and adapt to new contexts, is required to face this new reality. This new challenges mean that the Armed Forces should employ highly skilled and trained professionals to perform their missions.

The purpose of this article is to make a reflection about the professionalization process developed by the Portuguese Armed Forces, with special emphasis on their real protagonists: the military. Specifically, this study aims to characterize the young people who join the Armed Forces, their motivations and expectations.

\section{ÍNDICE}

Palavras-chave: Forças Armadas, profissionalização, escolhas profissionais, militares

Keywords: Armed Forces, professionalization, professional choices, military 